\title{
Effects of Evocative Audio-Visual Installations on the Restorativeness in Urban Parks
}

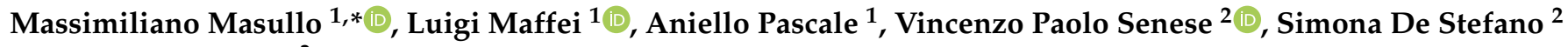 \\ and Chi Kwan Chau ${ }^{3}$ \\ 1 Department of Architecture and Industrial Design, University of Study of Campania "Luigi Vanvitelli", \\ 81031 Aversa, Italy; luigi.maffei@unicampania.it (L.M.); aniello.pascale@unicampania.it (A.P.) \\ 2 Department of Psychology, University of Study of Campania "Luigi Vanvitelli", 81100 Caserta, Italy; \\ vincenzopaolo.senese@unicampania.it (V.P.S.); simona.destefano@studenti.unicampania.it (S.D.S.) \\ 3 Department of Building Services Engineering, Hong Kong Polytechnic University, Kowloon, Hong Kong; \\ chi-kwan.chau@polyu.edu.hk \\ * Correspondence: massimiliano.masullo@unicampania.it
}

Citation: Masullo, M.; Maffei, L.; Pascale, A.; Senese, V.P.; De Stefano, S.; Chau, C.K. Effects of Evocative Audio-Visual Installations on the Restorativeness in Urban Parks. Sustainability 2021, 13, 8328. https:// doi.org/10.3390/su13158328

Academic Editors: Juan Miguel Navarro and Jaume Segura-Garcia

Received: 17 June 2021

Accepted: 21 July 2021

Published: 26 July 2021

Publisher's Note: MDPI stays neutral with regard to jurisdictional claims in published maps and institutional affiliations.

Copyright: (c) 2021 by the authors. Licensee MDPI, Basel, Switzerland. This article is an open access article distributed under the terms and conditions of the Creative Commons Attribution (CC BY) license (https:/ / creativecommons.org/licenses/by/ $4.0 /)$.

\begin{abstract}
Road traffic noise is responsible for several negative health effects for citizens in modern cities. Inside urban parks, which citizens use for social inclusion and cohesion, psychological and physical restoration, and physical activities, road traffic noise may significantly reduce the potential of these places to induce or enhance well-being. Although access restriction schemes and screens could be effective solutions to limit noise inside urban park areas, preserving their potential regenerative role may engender mobility, social, aesthetic, and architectural issues. Due to the positive effects that natural elements and water sounds can have on human perception, and based on the previous findings of the beneficial effects of audio-visual installations, this paper investigates the possibility of using audio-visual installations that simply evoke some natural features to improve the restoration of individuals inside urban parks. The study has been carried out using immersive virtual environments in two different experimental laboratory sessions in Hong Kong (China) and Aversa (Italy). The results showed that the positive effects provided by evocative installations were similar to those provided by traditional installations. Furthermore, the effects on the restoration increased as the installations became larger and included enveloping shapes. Furthermore, we found that the amount of evocative water installations' material was responsible for changes in restoration. In contrast, the Chinese groups were less influenced by these installations.
\end{abstract}

Keywords: urban parks; restorativeness; informational masking

\section{Introduction}

Road traffic noise is one of the most relevant environmental issues in large urban areas. It is responsible for an increasing risk in physiological and psychological health outcomes for the citizens of all of Western Europe, due to is effects on sleep disturbance, annoyance, ischaemic heart disease, cognitive impairment of children, and tinnitus [1]. Since the Directive 2002/49/EC (END) [2], considerable efforts have been carried out by EU member states to assess and manage environmental noise within cities and along the main transportation infrastructures. With the END having also been introduced for the first time in legislation, the term "quiet areas" (of agglomerations) has been introduced as delimiting areas not exposed to a value of Lden (Day-Evening-Night Level) or other noise indicators greater than a specific value. However, over the years, the definition of quiet areas has been extended [3] to broader alternative criteria which fit more closely to what the public experiences, such as for "tranquil areas" [4] and the "calm areas" [5]. In the Technical report of 2014 [6] and 2016 [7], EEA states clearly that noise level is not adequate to classify a calm area. Besides the noise levels in [8], EEA has identified a set of criteria to define potential quiet urban areas (e.g., open space, aesthetic value, accessibility and walking distance, size). Urban parks fit all these criteria. 
In densely populated and congested cities, urban parks represent, for citizens and other visitors, strategic places that they use for physical activities [9-13], to get mental and physical recovery [14-18], and for social inclusion and cohesion [19-21]. Several researches have shown that most of them do not comply with the noise limit issued by national legislation for protected areas [22-24] and that the higher incidence of this noise is due to the road traffic [25,26] and less from other environmental sources [27]. It is then crucial to preserve the role of the urban parks by introducing specific noise mitigating solutions. Although noise maps are the most frequently used diagnostic tools to describe, in the average, citizens' noise exposure, they consider the sound levels of noise only. More recently, several researchers have used subjective assessments to noise as new tools for spatial planning and decision support such as new indexes [28-31] and perceptual maps $[32,33]$. Urban authorities often use sustainable urban transport measures to minimise noise in city parks [34], or traditional strategies to limit the noise emission at the source and along the sound propagation paths. These limitations are based on traffic flows limitations, such as access restriction schemes (ARSs) (e.g., Low Emission Zones (LEZs), Congestion Charging Zones (CCZs); and Zero-Emission Zones (ZEZ)) [35,36], or the proposition of using integrated barriers [25] to separate the park from the surrounding road traffic. These solutions often have consequences on the aesthetic of places, urban mobility, local economy, and perception of safety. For these reasons, local public authorities are continuously looking for alternative solutions capable of mitigating road traffic noise effects within urban parks. One opportunity is provided by a paradigm shift, wherein the physical mitigation of noise is overcome and where audio and visual features are introduced to improve the perception of the environments [37].

The literature on this subject has demonstrated the positive effects of the natural elements on human health, well-being, and quality of life [38,39]. Natural sounds have been used in urban contexts to mitigate noise annoyance by exploiting the principle of informative masking (IM) of the sound [40], where a not energetic "masking sound" is intended to orient the attention of listeners rather than to mask it energetically. Among the best sounds, in a listening test, De Coensel et al. [41] showed that water and bird sounds may reduce the loudness of road traffic noise, especially if the traffic has low temporal variability, such as for freeway and major roads. Analysing different kinds of water sounds, Watts et al. [42] observed improvements in the tranquillity rating even if the water sounds were $7 \mathrm{~dB}(\mathrm{~A})$ below the background traffic noise levels due to the distracting effect of natural sound on traffic noise. The researchers converge to establish that the best effects can be obtained with the sound level of masker sound in range of $0 \div-3 \mathrm{~dB}$ [43-45] with respect to the background traffic noise. Water sounds can be differently identified (e.g., natural stream sounds are easily identifiable, unlike waterfalls and fountains) [46] or perceived as pleasant or unpleasant. For instance, when pleasant water sounds were added to road traffic noise, they positively affected the sound environment's overall pleasantness [47]. This is due to the temporal and spectral characteristics of water noise. The sharpness of water sound has proved to be a dominant factor for urban soundscape perception. Water sounds with low sharpness and large temporal variation, such as sea and water stream sound, were highly effective for IM of road traffic noise and, in general, preferable to fountains and waterfalls [48].

Besides the auditory elements, the attention restoration theory (ART) of Kaplan [49] and Ulrich's stress recovery theory [50] have demonstrated that environments including natural features are considered more restorative [51] than urban built environments [52], also showing positive effects on stress and cognition. In this light, green (e.g., trees, grass, vegetation) [53,54] and blue (e.g., water, sea, river) [55-57] elements are key elements of urban parks that can be exploited for their positive effects.

Recent multisensory research has attempted to explain the complex role of elementary stimuli on mental restoration, emotions, and human behaviours. Zhang et al. [58], conducting an on-site face-to-face and online survey on 250 users of Tianhe Park in Guangzhou, China, and showed that auditory sensations contributed to greater mental restoration than 
visual and tactile ones. Lugten et al. [59], in a virtual reality experiment, explored the effects of the audio and visual perception of natural elements inside an urban area exposed to aircraft noise. This study showed significant improvements (e.g., reducing the saliency of aircraft flyovers) when the vegetation and the moving water were present and when vegetation and moving water were presented simultaneously.

Preliminary research on the use of alternatives noise mitigation strategies in immersive virtual environments (IVE) have confirmed that adding water sounds at $-3 \mathrm{~dB}$ with respect to road traffic noise is possible to improve restorativeness [60] as well as the positive effects of adding the visual component (e.g., with the same sound stimulus, the installations of generous size enveloping the observer, resulted in having a better effect on individuals) [61]. These effects have been recently found to be attenuated by personality traits (e.g., extroversion) [62]. While green elements characterise most urban parks, the widespread use of water elements has some practical limitations due to the costs of realisation and maintenance of fountains or small water basins. Adopting the same approach of previous studies [63-67] which ensures the ecological validity of the experiments [68,69], this paper investigates the effects of the potential use of evocative audio-visual installations on restorativeness. Two laboratory experiments were conducted both in Italy and Hong Kong in order to answer the following questions:

Research Question 1 (RQ1). To what extent do the introduction of evocative audio-visual installations that do not use water, but water sounds and materials that visually mimic water, influence the perceived restorativeness of an urban park? Which installations provide the best results on restorativeness?

Research Question 2 (RQ2). To what extent does the amount of material of the evocative installations affect the observer/listeners restorativeness? How does restorativeness change as the amount of material increase?

A third question refers to the comparison of the results between the two Italian and Chinese groups.

Research Question 3 (RQ3). Do evocative installations have the same effects on the restorativeness of Italian and Chinese groups?

\section{Study 1}

The first study aimed to investigate to what extent the introduction of evocative audio-visual installations that do not use water, but rather water sounds and materials that visually mimic water, influenced the perceived restorativeness of an urban park. To this aim, six different 3D models (scenarios) to be presented as an immersive audiovisual environment were created (see Table 1), one presenting the basic scenario (BS) simulating the considered urban park as it was (visually and auditory) and five others that included audio-visual installations. The latter scenarios were created by combining visual installations and water sounds. In particular, two of them were generated by adding to the basic scenario elements representing realistic (water movement is clearly perceivable) water installations (WI-1, see Figure 1a,c; WI-2, see Figure 1b,d and the relative sounds, whereas the other three were generated by adding to the basic scenario three types of (static) elements representing evocative water installations (EWI-1, see Figure 2a; EWI-2, see Figure 2b; EWI-3, see Figure 2c) and the relative sounds. Therefore, water installations and evocative water installations were generated by combining five types of visual information (V) and two types of auditory stimuli (A).

To verify the effect of the evocative audio-visual installations on the perceived restorativeness, the six different scenarios were presented to participants (one by one) using an immersive audio-visual virtual reality equipment. A standardised scale was administered to measure the degree of restorativeness associated with each scenario. 


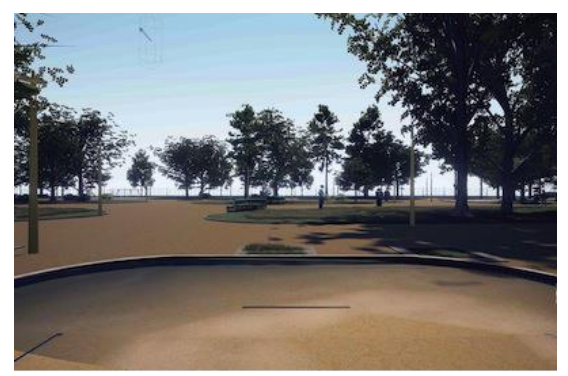

(a)

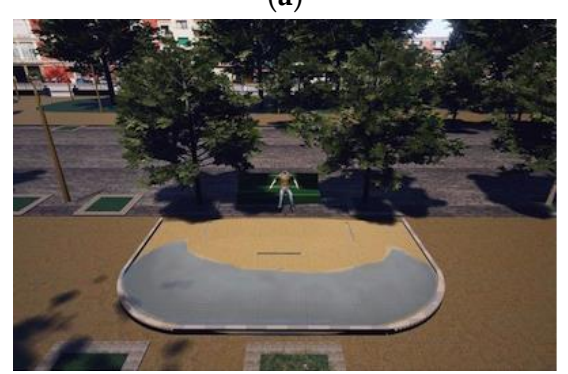

(c)

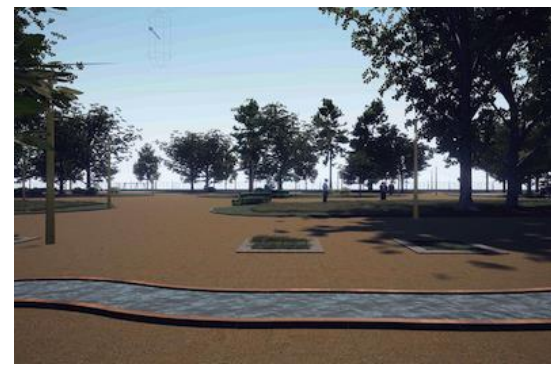

(b)

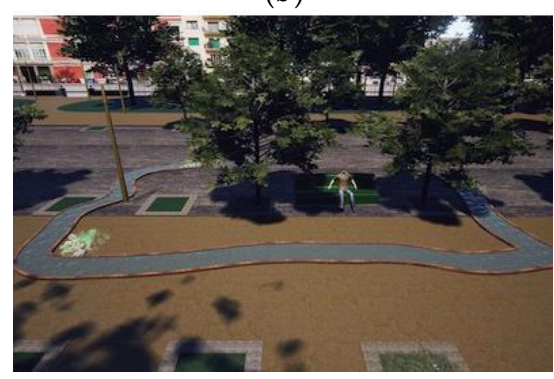

(d)

Figure 1. Installations with realistic water features from the participant's perspective $(\mathbf{a}, \mathbf{b})$ and bird's eye view (c,d).

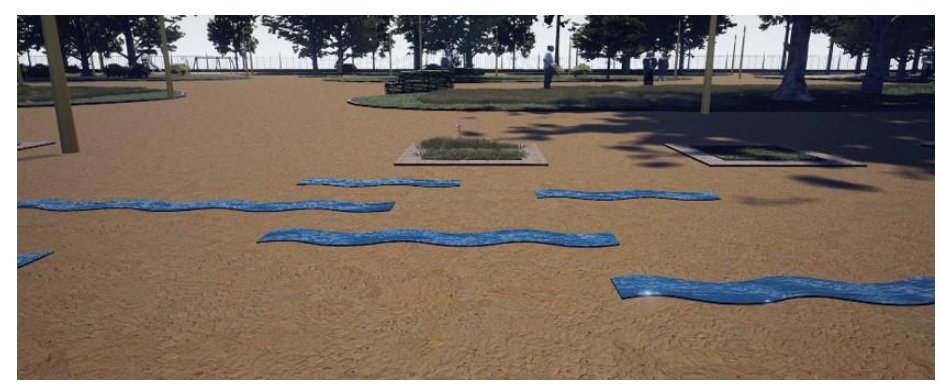

(a)

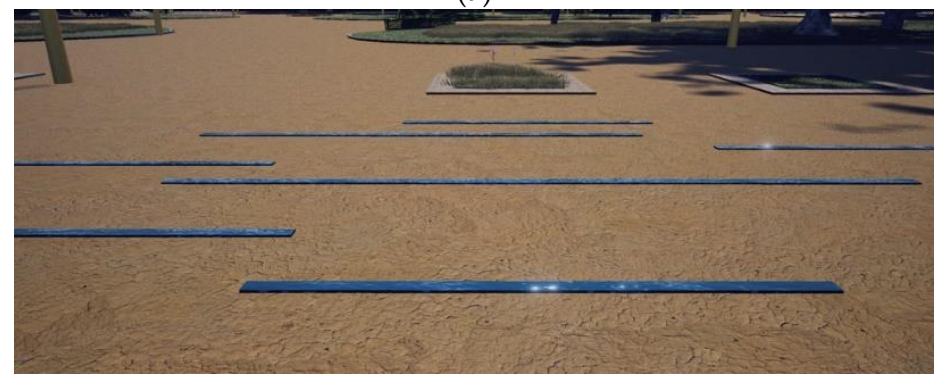

(b)



(c)

Figure 2. Evocative water installations: EWI-1 (a), EWI-2 (b), and EWI-3 (c). 
Table 1. Scheme of scenarios configuration.

\begin{tabular}{ccc}
\hline Scenario & Visual Stimuli & Auditory Stimuli \\
\hline BS & $\mathrm{V}_{0}$ & $\mathrm{~A}_{0}$ \\
WI-1 & $\mathrm{V}_{0}+\mathrm{V}_{1}$ & $\mathrm{~A}_{0}+\mathrm{A}_{1}$ \\
WI-2 & $\mathrm{V}_{0}+\mathrm{V}_{2}$ & $\mathrm{~A}_{0}+\mathrm{A}_{2}$ \\
EWI-1 & $\mathrm{V}_{0}+\mathrm{V}_{3}$ & $\mathrm{~A}_{0}+\mathrm{A}_{1}$ \\
EWI-2 & $\mathrm{V}_{0}+\mathrm{V}_{4}$ & $\mathrm{~A}_{0}+\mathrm{A}_{1}$ \\
EWI-3 & $\mathrm{V}_{0}+\mathrm{V}_{5}$ & $\mathrm{~A}_{0}+\mathrm{A}_{2}$ \\
\hline
\end{tabular}

Based on the previous literature, we expected that Wis would increase the level of restorativeness compared to the basic scenario and that EWIs would have a similar effect to WIs. Furthermore, to verify the results' replicability and assess whether cultural factors moderated the effect of the evocative audio-visual installations on perceived restorativeness, the same experiment was carried out in two different countries (Italy and China). As regards this latter comparison, we did not expect any significant differences across countries.

\subsection{Methods}

\subsubsection{Participants}

Forty-eight adults aged between 19 and 47 were recruited for the study ( 21 females and 27 males). Participants were sampled in two different countries: Italy ( $n=24 ; 7$ females and 17 males) and China ( $n=24 ; 14$ females, and 10 males). All participants gave their consent to take part in the study. The participants were mainly students recruited from university courses of the two departments where the experiments were conducted, who were asked to participate without any incentives.

\subsubsection{Procedure}

The experiment was carried out in silent rooms located in the Department of Architecture and Industrial Design of the University of Study of Campania (for the Italian Sessions, ITA) and the Department of Building Services Engineering of the Hong Kong Polytechnic University (for the Chinese Sessions, HK). Before starting the individual experimental session, a questionnaire developed to collect basic demographic information was administered to each participant (e.g., gender, age, residence zone). Afterwards, participants were invited to sit on a chair, and written instructions describing the procedure and the data collection process were provided. After that, participants wore a head-mounted display to be immersed in the basic virtual scenario. The subject was virtually seated on a bench inside the park. It was invited to freely explore the virtual environment by moving the head for a minute before starting the testing session. In this way, participants became familiarised with the virtual environment (basic scenario). After that, the test started. Participants were invited to look around in the scenario for $15 \mathrm{~s}$, and after that the experimenter started their evaluation of the restorativeness. Participants were presented (auditorily) the first item of the short version of the perceived restorativeness scale PRS-11 [70] and were asked to respond by voice to the item. The experimenter registered the response. Participants had no time limit to respond to each item. After each item presentation, they were free, by rotating their head, to explore the environment for as long as needed. Once they answered, the experimenter presented the next item of the scale. After that, when the participant had answered all the items of the PRS-11, the experimenter changed the scenario and the same procedure was repeated. The sequence of the administration of the six scenarios (BS, WI- 1 , WI-2, EWI-1, EWI-2, EWI-3) was balanced according to a Latin square. The experimental session lasted about $20 \mathrm{~min}$ for each participant, and the experimenter supervised and helped participants when necessary.

\subsubsection{Setting and Apparatus}

Graphical stimuli. From the available plans and on-site surveys, a reconstruction of an urban park in Naples, the "Villa Comunale", was carried out and used as the basic scenario 
(BS). Starting from Archicad modelling software, all of the geometries were modelled. Later, within 3DsMax, all the 3D elements were optimised and mapped to be correctly imported into Unreal Engine 4 development software as assets (Figure 3). Here, the scenario was built. It has been recreated according to the natural lighting system, the animations of the traffic flow and all of the interactions for the experiment management were coded. For example, visual variables (described below for each study) were introduced from time to time within the basic environment, smoothly managed by the operator using a keyboard.
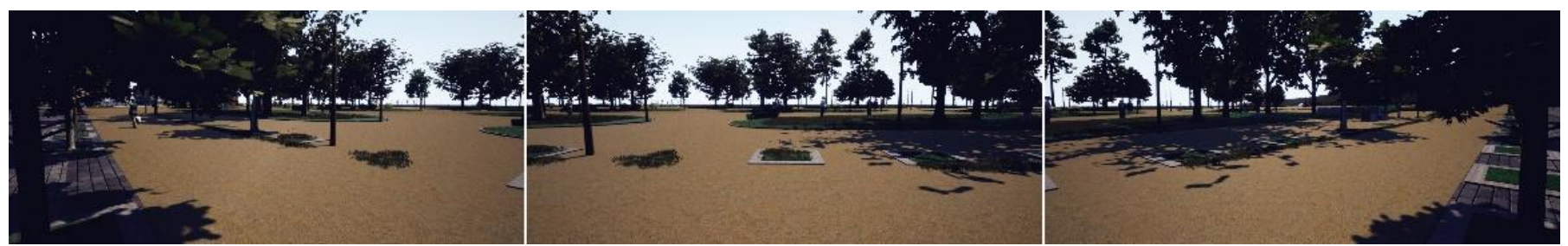

Figure 3. Images of the basic scenario (BS) of the "Villa Comunale" from the participants' perspective.

The basic scenario (BS) had a rectangular shape, and was surrounded by trafficked roads (Figure 4). The interior space of the Villa Comunale is organised with a main central corridor and other parts with smaller paths where, on the sides, people can sit on benches. The natural environment is dominant, although vehicular traffic is barely visible from many points of view. All of the elements of the existing situation have been inserted into the 3D model, and a bench has been chosen as a subjective point for the experiments. It is oriented toward the inner part of the park. This is a common orientation of the park benches to limit the vision of the traffic by visitors. The head-mounted display (Oculus Rift) was used by participants to experience the virtual reality scenarios.

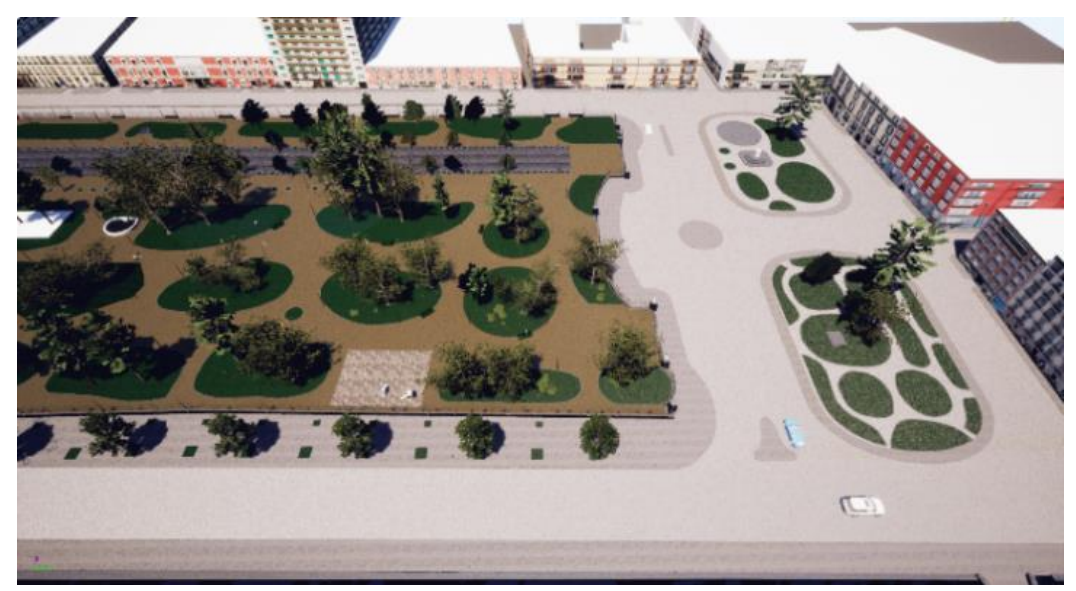

Figure 4 . The 3D virtual model of the Villa Comunale.

Audio stimuli. To add the background sound (A0) of the basic environment, some recordings have been carried out within the park by a Zoom H6 recorder equipped with a Soundfield SPS200 microphone. The recordings consist of surrounding road traffic noise. At the same time, to determine the sound equivalent level of recordings, a sound level

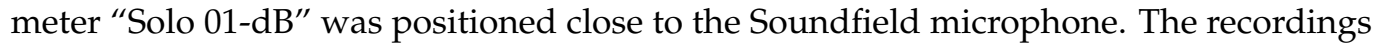
were carried out at nine distinct positions within the park. The levels measured in different points varied from a range of $67-71 \mathrm{~dB}(\mathrm{~A})$ for the external points (located near the road) and from 58 to $59 \mathrm{~dB}(\mathrm{~A})$ for the most internal points.

A 5.1 configuration has been built into the virtual world for reproduction (Figure 5a), positioning virtual loudspeakers around the participant position. The directivity of each virtual loudspeaker has been set according to the directivity diagram of a real speaker, Dynaudio Xeo3. To overcome the limits of the software Unreal Engine 4 to reproduce in 
detail the directivity of the loudspeakers, each audio signal was decomposed among three audio assets. The assets reproduce the directivity at low, medium, and high frequencies. The auditory stimuli were reproduced by means of a headphone Sennheiser HD201, and the reproduction sound level (Leq) was calibrated by means of a Mk1 Cortex dummy head before starting the experiments (Figure $5 b$ ).

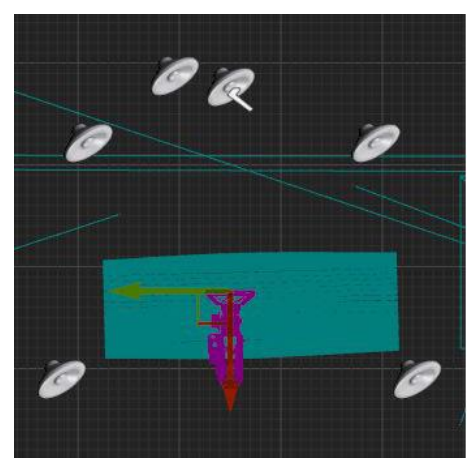

(a)

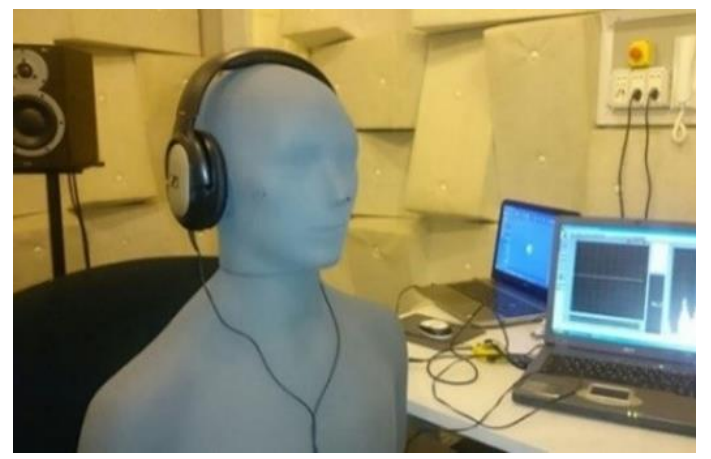

(b)

Figure 5. The 5.1 virtual configuration (a) and the headphones calibration (b).

Masking sounds. In a preliminary study, we have carried out an experiment to evaluate the effects on the restorativeness of a sample of water sound, among distinct categories [71]. All of the sounds were downloaded from an online available sound library. The results showed that two categories of natural sound (Sea Sound, Stream Sound) increase the restorativeness more than others investigated categories (Jet fountain, Waterfall fountain). For the following series of experiment, we used the same sounds of the previous one, reproducing the sound of the stream flowing (A2) and the sea movement on the shoreline (A1). In line with the literature [37,52,53], the sound levels of the masking water sound were set around $55.0 \mathrm{~dB}(\mathrm{~A})$, at about $-3 \mathrm{~dB}$ of the background road traffic noise.

\subsubsection{Measures}

Perceived Restorativeness Scale. To evaluate the restorativeness of the urban park, the short version of the perceived restorativeness scale [70] was administered. Starting from the original Hartig's version of the scale [72] focused on the four-factors of attention restoration theory (ART) (Fascination, Being-Away, Extent and Compatibility), the short version of the scale evaluates perceived restorativeness as reflecting four factors: the Fascination (three items), Being-Away (three items), Coherence (three items) and Scope (two items). As in the extended version of the scale, items present statements to which individuals have to indicate their degree of agreement on a 10 points-scale with both numerical and semantic anchoring (from $0=$ "not at all" to $10=$ "completely"). A total score was computed for each dimension where high values indicated a respectively higher fascination, being-away, coherence and scope associated with a target environment. Items were presented auditorily. To this aim, each sentence of the scale was read aloud and recorded using a sound recorder into the anechoic chamber to be presented to participants.

\subsubsection{Data Analysis}

Descriptive analyses were carried out to investigate variables distributions, the presence of outliers, and missing values [73]. To analyse main and interactive effects of the scenario, sex and population factors on the restorativeness scores, four mixed factorial $6 \times 2 \times 2$ ANOVAs that treated Scenario as a 6-level within-subject factor (BS, WI-1, WI-2, EWI-1, EWI-2, EWI-3), Sex as a 2-level between-subject factor (Males vs. Females) and Population as a 2-level between-subject factor (Italian vs. Chinese) were carried out. For each analysis, one of the scores of the four subscales of the PRS-11 (Fascination, Being-Away, Coherence or Scope) was considered. Sidak correction was applied to analyse post hoc 
effects. The magnitude of significant effects was indicated by partial eta squared $\left(\eta^{2} \mathrm{p}\right)$. All tests were two-sided, with an alpha level of 0.05 .

\subsection{Results}

Main descriptive statistics as a function of the restorativeness dimensions and the scenario are reported in Table 2. Data did not show missing values or distribution problems for the considered variables.

Table 2. Descriptive statistics (Mean [M], Standard Deviation [SD], Skewness [S] and Kurtosis [K]) of the restorativeness scores.

\begin{tabular}{|c|c|c|c|c|c|c|c|c|c|c|c|c|c|c|c|c|}
\hline \multirow{2}{*}{ Scenario } & \multicolumn{4}{|c|}{ Fascination } & \multicolumn{4}{|c|}{ Being-Away } & \multicolumn{4}{|c|}{ Coherence } & \multicolumn{4}{|c|}{ Scope } \\
\hline & $\mathbf{M}$ & SD & $S$ & $\mathbf{K}$ & $\mathbf{M}$ & SD & $S$ & $\mathbf{K}$ & $\mathbf{M}$ & SD & $S$ & $\mathbf{K}$ & $\mathbf{M}$ & SD & $S$ & $\mathbf{K}$ \\
\hline $\mathrm{B}$ & 528 & 1.47 & 0.3 & .26 & 5.19 & 139 & 45 & 06 & 5.08 & 25 & 07 & 086 & 4.99 & 1.36 & 0.37 & -0.35 \\
\hline WI-1 & 4.83 & 1. & & & 5.53 & & -0.34 & & 5.72 & & 0.13 & & 5.22 & 1.56 & 1 & 0.90 \\
\hline WI-2 & 5.48 & 1.04 & 0.09 & -0.32 & 6.25 & 1.52 & 0.45 & -0.3 & 6.12 & 1.83 & 0.00 & -0.74 & 5.74 & 1.55 & 0.23 & -0.53 \\
\hline EWI-1 & 4.91 & 1.37 & 0.15 & -0.25 & 5.35 & 1.32 & -0.32 & 0.42 & 5.58 & 1.58 & 0.30 & 0.28 & 4.95 & 1.46 & -0.6 & 0.63 \\
\hline EWI-2 & 5.24 & 1.26 & -0.05 & -0.72 & 5.89 & 1.28 & -0.10 & -0.9 & 5.80 & 1.66 & 0.23 & -0.69 & 5.31 & 1.27 & 0.51 & -0.19 \\
\hline EWI-3 & 5.19 & 1.26 & -0.06 & -0.60 & 5.33 & 1.70 & -0.51 & -0.2 & 5.40 & 1.72 & -0.1 & 0.29 & 4.84 & 1.49 & -0.2 & 0.29 \\
\hline
\end{tabular}

Fascination. The ANOVA on the fascination scores revealed a significant main effect of the scenario, $F(5,220)=3.26, p=0.007, \eta^{2} \mathrm{p}=0.069$, and the population, $F(1,44)=23.56$, $p<0.001, \eta^{2}{ }_{p}=0.349$; not significant were the main effect of the sex, $F(1,44)=2.28, p=0.138$, $\eta^{2} \mathrm{p}=0.049$, or the other interactions effects. The post hoc tests of the scenario effect (see Table 2) showed that, independently of the sex and population, the scenario with the highest fascination scores was the WI-2, which showed significantly higher values than scenarios EWI-1 and WI-1. No significant differences were observed between the basic scenario (BS) and the scenarios with water installations (WIs) or with the evocative water installation (EWIs). Comparing the mean values computed as a function of the population indicated that, independently of the scenario and the sex, Italian participants $(M=5.9)$ evaluated all the scenarios as more fascinating than the Chinese participants $(M=4.6)$.

Being-Away. The ANOVA on the being-away scores revealed a significant main effect of the scenario, $F(5,220)=7.69, p<0.001, \eta^{2} p=0.149$, the population, $F(1,44)=44.40$, $p<0.001, \eta^{2}=0.502$, and the Sex, $F(1,44)=4.18, p=0.047, \eta^{2} p=0.087$; not significant were the interactions effects. The post hoc tests of the scenario effect (see Table 2) showed that, independently of the sex and population, the scenario with the highest being away scores was the WI-2, which showed significantly higher values than the basic scenario (BS), WI-1, EWI-1, EWI-3. No significant difference was observed between WI-2 and EWI-2. The latter scenario showed significantly higher values than the basic scenario (BS) and EWI-1. The comparison of the mean values computed as a function of the population indicated that, independently of the scenario and the sex, Italian participants $(M=6.6)$ showed higher scores on the being-away dimension for all the scenarios than Chinese participants $(M=4.8)$. The comparison of the mean values computed as a function of the sex indicated that, independently of the scenario and the population, females $(M=6.0)$ showed higher scores on the being-away dimension for all the scenarios than males $(M=5.4)$.

Coherence. The ANOVA on the coherence scores revealed a significant main effect of the scenario, $F(5,220)=9.34, p<0.001, \eta^{2} \mathrm{p}=0.175$, the population, $F(1,44)=56.99$, $p<0.001, \eta^{2} \mathrm{p}=0.564$, and the sex, $F(1,44)=5.34, p=0.026, \eta^{2} \mathrm{p}=0.108$; not significant were the interactions effects. The post hoc tests of the scenario effect (see Table 2) showed that, independently of the sex and population, the scenario with the highest coherence scores was the WI-2, which showed significantly higher values than the basic scenarios (BS), EWI-1 and EWI-3. No significant differences were observed between WI-2, WI-1 and EWI-2. The latter scenario showed significantly higher values than the basic scenario (BS). The comparison of the mean values computed as a function of the population indicated that, independently of the scenario and the sex, Italian participants $(M=6.9)$ showed higher scores on the coherence dimension for all the scenarios than Chinese participants 
$(M=4.6)$. The comparison of the mean values computed as a function of the sex indicated that, independently of the scenario and the population, females $(M=6.1)$ showed higher scores on the coherence dimension for all the scenarios than males $(M=5.4)$.

Scope. The ANOVA on the scope scores revealed a significant main effect of the scenario, $F(5,220)=4.54, p=0.001, \eta^{2} p=0.094$, the population, $F(1,44)=24.29, p<0.001$, $\eta^{2} \mathrm{p}=0.356$, and the sex, $F(1,44)=4.31, p=0.044, \eta^{2} \mathrm{p}=0.089$; not significant were the interactions effects. The post hoc tests of the scenario effect (see Table 2) showed that, independently of the sex and population, the scenario with the highest scores on the scope dimension was the WI-2, which showed significantly higher values than scenarios EWI-1 and EWI-3. No other significant differences were observed. The comparison of the mean values computed as a function of the population indicated that, independently of the scenario and the sex, Italian participants $(M=6.0)$ showed higher scores on the scope dimension for all the scenarios than Chinese participants $(M=4.6)$. Finally, comparing the mean values computed as a function of the sex indicated that, independently of the scenario and the population, females $(M=5.6)$ showed higher scores on the scope dimension for all the scenarios than males $(M=5.0)$.

\subsection{Discussion}

This first VR experiment highlighted how the introduction of water installations in a basic scenario where water elements (e.g., fountains, basins. small rivers) are absent might improve most components of restorativeness. In line with previous studies, the results showed that not all of the water installations led to the same positive improvements.

For instance, WI-2 provided improvements in the being-away and the coherence, while WI-1 did not.

Regarding the evocative installations, the EWI-2 which uses blue material over the largest occupied apparent area (which is the area that circumscribes all the fragments of the installation from the participant's point of view), received, statistically, similar scores to the preferred water installation WI-2. The installation, which uses the thickest blue fragments, instead, seem to improve especially the fascination.

At the same time, the big differences between the two populations put in evidence that the general preference toward these installations produces a weaker improvement in all the restorativeness components for the Chinese group (from $-1,3$ points for fascination to $-2,3$ points for coherence) than the Italian. Except for fascination, females were more positively influenced by WI and EWI installation (about $+0,6$ points) than males.

\section{Study 2}

Study 1 showed that evocative installations (EWI) could have similar restorativeness effects to real water installations (WI) when introduced in the urban parks. However, the effects of the installations' size, and of the amount of material that they use, are less clear. This second experiment compared two water installation with different occupied apparent areas and evaluated the effect of different amount of material used. To this aim, two installations with real water (sea-water fountain, WI-1, and a stream, WI-2) (Figure 6), and six installations with resin tiles, were created as a 3D model and presented to participants using the same immersive audio-visual virtual reality equipment used in the previous study. All of the scenarios were created starting from the same basic scenario (BS) used in Study 1 (see Table 3).

To better simulate the water surface effect, hexagonal dark-blue tiles of about $0.03 \mathrm{~m}^{2}$ were used. The evocative installations were created by graduating three levels $(30 \%, 60 \%$, and $100 \%$ ) of the surface area covered by the tiles. This resulted in the development of six scenarios: EWI-1-30, EWI-1-60, EWI-1-100 and EWI-2-30, EWI-2-60, EWI-2-100 for WI-1 and WI-2 (see Figure 7). 


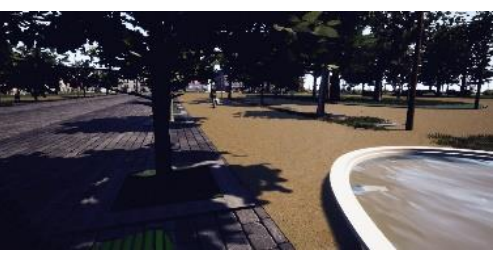

(a)

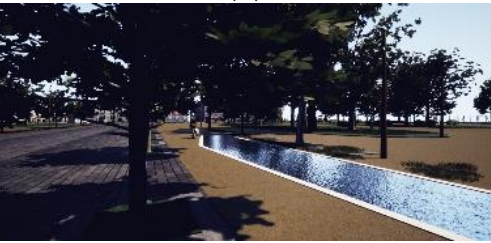

(d)

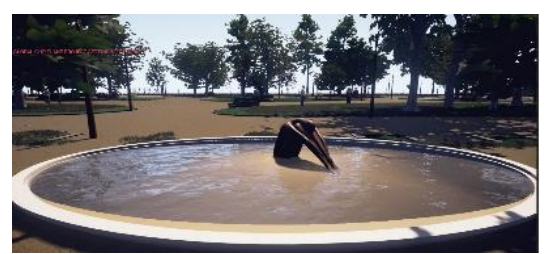

(b)

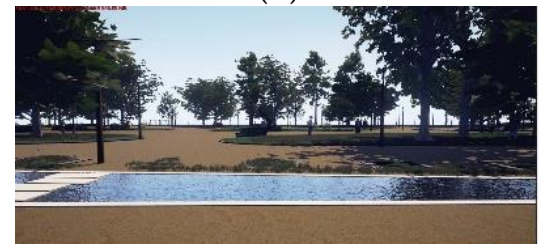

(e)

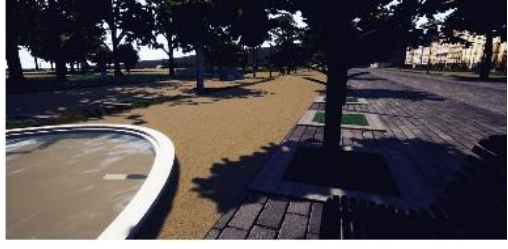

(c)

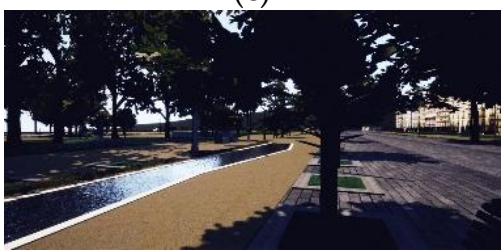

(f)

Figure 6. Installations with real water features. Sea-water fountain, WI-1 ((a), left view; (b), frontal view and (c), right view) and stream, WI-2 ((d), left view; (e), frontal view and (f), right view).



(a)

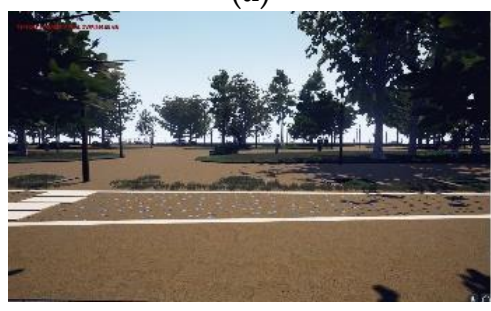

(d)



(b)

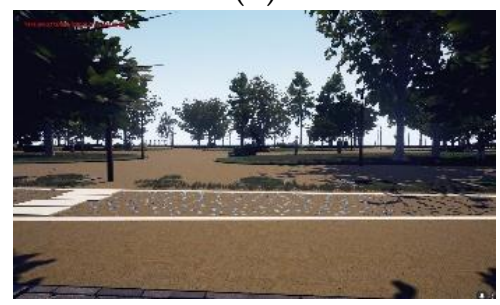

(e)

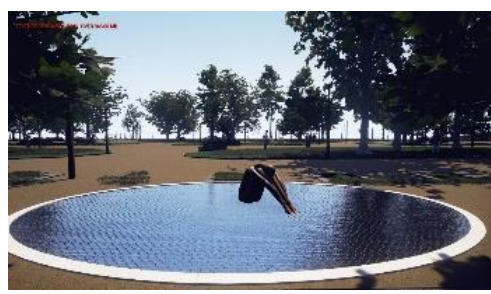

(c)

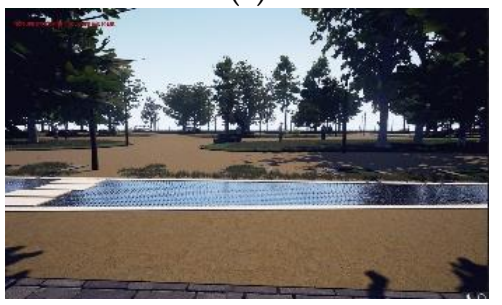

(f)

Figure 7. Installations with evocative water tiles. Frontal view of the sea-water fountain, EWI-1: (a) 30\%, EWI-1-30; (b) 60\%, EWI-1-60; (c) 100\%, EWI-1-100. Frontal view of the stream EWI-2: (d) 30\%, EWI-2-30; (e) 60\%, EWI-2-60; (f) 100\%, EWI-2-100.

Table 3. Scheme of scenarios configurations.

\begin{tabular}{|c|c|c|c|c|c|c|}
\hline Scenario & Auditory Stimuli & Visual Stimuli & Type Installation & Type Coverage & $\begin{array}{c}\text { Amount Coverage } \\
(\%)\end{array}$ & $\begin{array}{c}\text { Surface Covered } \\
\left(\mathrm{m}^{2}\right)\end{array}$ \\
\hline WI-1 & $\mathrm{A}_{0}+\mathrm{A}_{2}$ & $\mathrm{~V}_{0}+\mathrm{V}_{1}$ & Sea-water fountain & Water & $100 \%$ & 140 \\
\hline EWI-1-30 & $\mathrm{A}_{0}+\mathrm{A}_{2}$ & $\mathrm{~V}_{0}+\mathrm{V}_{2}$ & Sea-water fountain & Tiles & $30 \%$ & 42 \\
\hline EWI-1-60 & $\mathrm{A}_{0}+\mathrm{A}_{2}$ & $\mathrm{~V}_{0}+\mathrm{V}_{3}$ & Sea-water fountain & Tiles & $60 \%$ & 84 \\
\hline EWI-1-100 & $\mathrm{A}_{0}+\mathrm{A}_{2}$ & $\mathrm{~V}_{0}+\mathrm{V}_{4}$ & Sea-water fountain & Tiles & $100 \%$ & 140 \\
\hline WI-2 & $\mathrm{A}_{0}+\mathrm{A}_{1}$ & $\mathrm{~V}_{0}+\mathrm{V}_{5}$ & Stream & Water & $100 \%$ & 29 \\
\hline EWI-2-30 & $\mathrm{A}_{0}+\mathrm{A}_{1}$ & $\mathrm{~V}_{0}+\mathrm{V}_{6}$ & Stream & Tiles & $30 \%$ & 9 \\
\hline EWI-2-60 & $\mathrm{A}_{0}+\mathrm{A}_{1}$ & $\mathrm{~V}_{0}+\mathrm{V}_{7}$ & Stream & Tiles & $60 \%$ & 17 \\
\hline EWI-2-100 & $\mathrm{A}_{0}+\mathrm{A}_{1}$ & $\mathrm{~V}_{0}+\mathrm{V}_{8}$ & Stream & Tiles & $100 \%$ & 29 \\
\hline
\end{tabular}

Finally, due to the results of Study 1, which showed significant differences as a function of sex and population, in this second Study 2, a quota sampling procedure was followed to get the same number of individuals in the male and female groups balanced on the population factor. 


\subsection{Method}

\subsubsection{Participants}

One hundred adults aged between 19 and 41 were recruited for the study (49 females, 51 males). Participants were sampled in two different countries: Italy $(n=52 ; 28$ females and 24 males) and China ( $n=48 ; 21$ females and 27 males). Participants gave written consent to take part in the study. There was no incentive for participation.

\subsubsection{Procedure}

The second study was carried out following the same procedure as Study 1 except that the presented scenarios were different. The experimental session lasted about $22 \mathrm{~min}$ for each participant, and the experimenter supervised and helped participants when necessary.

\subsubsection{Setting and Apparatus}

Graphical stimuli. The same software and the same procedure were followed to develop the new installations' assets to be added to the basic scenario developed for Study 1.

Masking sounds. The same audio and the same procedure were followed to develop the scenarios.

\subsubsection{Measures}

Perceived Restorativeness Scale. The same measure and the same procedure followed in Study 1 were used to measure the perceived restorativeness associated with each considered.

\subsubsection{Data Analysis}

Descriptive analyses were carried out to investigate variables distributions, the presence of outliers and missing values [74]. To analyse main and interactive effects of scenario, sex and population on the restorativeness scores, four mixed factorial $8 \times 2 \times 2$ ANOVAs that treated scenario as an 8-level within-subject factor (WI-1, EWI-1-30, EWI-1-60, EWI-1100, WI-2, EWI-2-30, EWI-2-60, EWI-2-100), sex as a 2-level between-subject factor (Males vs. Females) and population as a 2-level between-subject factor (Italian vs. Chinese) were carried out. For each analysis, one of the scores of the four subscales of the PRS-11 (fascination, being-away, coherence or scope) was considered. Sidak correction was applied to analyse post hoc effects. The magnitude of significant effects was indicated by partial eta squared $\left(\eta^{2} \mathrm{p}\right)$. All tests were two-sided, with an alpha level of 0.05 .

\subsection{Results}

Main descriptive statistics as a function of the restorativeness dimension and the scenario are reported in Table 4. Data showed non-missing values or distribution problems.

Table 4. Descriptive statistics (Mean [M], Standard Deviation [SD], Skewness [S], and Kurtosis [K]) of the restorativeness scores.

\begin{tabular}{ccccccccccccccccc}
\hline \multirow{2}{*}{ Scenario } & \multicolumn{4}{c}{ Fascination } & \multicolumn{4}{c}{ Being-Away } & \multicolumn{4}{c}{ Coherence } & \multicolumn{4}{c}{ Scope } \\
\cline { 2 - 6 } & $\mathbf{M}$ & SD & S & K & M & SD & S & K & M & SD & S & K & M & SD & S & K \\
\hline WI-1 & 6.48 & 1.66 & -0.09 & -0.28 & 6.71 & 1.64 & -0.37 & 0.33 & 6.33 & 1.66 & -0.47 & -0.22 & 6.83 & 1.81 & -0.34 & 0.37 \\
EWI-1-30 & 5.10 & 1.96 & 0.30 & -0.49 & 5.61 & 1.92 & 0.13 & -0.53 & 5.26 & 1.89 & -0.24 & -0.22 & 6.38 & 1.97 & -0.15 & -0.41 \\
EWI-1-60 & 5.26 & 1.86 & 0.31 & -0.61 & 5.62 & 1.92 & -0.19 & -0.58 & 5.37 & 1.88 & -0.19 & -0.61 & 6.38 & 2.07 & -0.24 & -0.35 \\
EWI-1-100 & 6.40 & 1.47 & 0.07 & -0.65 & 6.61 & 1.66 & -0.83 & 0.54 & 6.44 & 1.63 & -0.27 & -0.48 & 7.00 & 1.69 & -0.28 & -0.08 \\
WI-2 & 6.67 & 1.41 & -0.35 & 1.64 & 6.99 & 1.55 & -0.70 & 0.22 & 6.95 & 1.39 & -0.34 & -0.09 & 7.35 & 1.53 & -0.27 & -0.02 \\
EWI-2-30 & 4.76 & 2.01 & 0.23 & -0.38 & 5.35 & 2.08 & -0.07 & -0.66 & 4.99 & 1.99 & -0.11 & -0.46 & 6.38 & 2.16 & -0.41 & -0.04 \\
EWI-2-60 & 5.05 & 1.84 & 0.07 & 0.27 & 5.47 & 1.99 & 0.04 & -0.63 & 5.64 & 1.76 & -0.10 & -0.56 & 6.53 & 1.97 & -0.30 & -0.10 \\
EWI-2-100 & 6.33 & 1.62 & -0.05 & 0.16 & 6.60 & 1.74 & -0.76 & 0.97 & 6.70 & 1.54 & -0.50 & -0.10 & 7.08 & 1.74 & -0.14 & -0.23 \\
\hline
\end{tabular}


Fascination. The ANOVA on the fascination scores revealed a significant main effect of the scenario, $F(7,672)=52.27, p<0.001, \eta^{2} p=0.353$, and the population, $F(1,96)=20.24$, $p<0.001, \eta^{2} \mathrm{p}=0.174$, and a significant scenario $\times$ population interaction, $F(7,672)=10.63$, $p<0.001, \eta^{2}{ }_{p}=0.100$; not significant were the main effect of the sex, $F(1,96)=1.40, p=0.240$, $\eta^{2} \mathrm{p}=0.014$, or the other interactions effects. The post hoc tests of the scenario effect (see Table 4) showed that, independently of the sex and population, the scenarios with the highest fascination scores were the scenarios WI-1, WI-2, EWI-1-100, and EWI-2-100, which showed significantly higher values than scenarios EWI-1-30, EWI-1-60, EWI-2-30, and EWI-2-60. The mean comparison computed as a function of the population indicated that, independently of the scenario and the sex, Italian participants $(M=6.3)$ evaluated all the scenarios more fascinating than the Chinese participants $(M=5.2)$. Finally, the post hoc tests of the scenario $\times$ population effect showed that Chinese participants evaluated as less fascinating than Italians all the installations of the sea-water fountain (WI-1, EWI-1-30, EWI-1-60, EWI-1-100) and the two evocative installations of the stream with less than 100\% of the covered surface (EWI-2-30 and EWI-2-60).

Being-Away. The ANOVA on the being-away scores revealed a significant main effect of the scenario, $F(7,672)=40.70, p<0.001, \eta^{2} p=0.298$, and the population, $F(1,96)=4.12$, $p=0.045, \eta^{2} \mathrm{p}=0.041$ and a significant scenario $\times$ population interaction, $F(7,672)=14.11$, $p<0.001, \eta^{2} p=0.128$; not significant were the main effect of the $\operatorname{sex}, F(1,96)=0.08, p=0.778$, $\eta^{2} \mathrm{p}=0.001$, or the other interactions effects. The post hoc tests of the scenario effect (see Table 4) showed that, independently of the sex and population, the scenarios with the highest being-away scores were the scenarios WI-1, WI-2, EWI-1-100, and EWI-2-100, which showed significantly higher values than scenarios EWI-1-30, EWI-1-60, EWI-2-30, and EWI-2-60. The mean comparison computed as a function of the population indicated that, independently of the scenario and the sex, Italian participants $(M=6.4)$ showed a higher being-away score to all the scenarios than Chinese participants $(M=5.8)$. Finally, the post hoc tests of the scenario $\times$ population effect showed that Chinese participants showed lower being-away scores than Italian for the evocative installations with less than $100 \%$ of the covered surface (EWI-1-30, EWI-1-60, EWI-2-30 and EWI-2-60).

Coherence. The ANOVA on the coherence scores revealed a significant main effect of the scenario, $F(7,672)=41.39, p<0.001, \eta^{2} p=0.301$, and the sex, $F(1,96)=4.28, p=0.041$, $\eta^{2}{ }_{p}=0.043$, and significant scenario $\times$ population, $F(7,672)=13.06, p<0.001, \eta^{2} p=0.120$, and sex $\times$ population interactions, $F(1,96)=4.85, p=0.030, \eta^{2} p=0.048$; not significant were the main effect of the population, $F(1,96)=2.02, p=0.159, \eta^{2} p=0.021$, or the interactions effects. The post hoc tests of the scenario effect (see Table 4) showed that, independently of the sex and population, the scenarios with the highest coherence scores were the scenarios WI-2 and EWI-2-100, which showed significantly higher values than all the other scenarios. The scenarios with the lowest coherence scores were EWI-2-30, EWI-1-30, and EWI-1-60. The mean comparison computed as a function of the sex indicated that, independently of the scenario and the population, females $(M=6.2)$ showed higher scores on the coherence dimension for all the scenarios than males $(M=5.7)$. The post hoc tests of the scenario $\times$ population effect showed that Chinese participants showed higher coherence score than Italians in the WI-2 and EWI-2-100 scenarios. In contrast, the opposite pattern was observed for the evocative installations with less than $100 \%$ of the covered surface (EWI-1-30, EWI1-60, EWI-2-30 and EWI-2-60). Finally, the post hoc tests of the sex $\times$ population effect indicated that sex differences on the coherence scores were observed only for Italians.

Scope. The ANOVA on the scope scores revealed a significant main effect of the scenario, $F(7,672)=13.44, p<0.001, \eta^{2} \mathrm{p}=0.123$, and the population, $F(1,96)=33.24$, $p<0.001, \eta_{\mathrm{p}}^{2}=0.257$, and significant scenario $\times$ population, $F(7,672)=5.80, p<0.001$, $\eta^{2}{ }_{p}=0.057$, and scenario $\times$ sex interactions, $F(7,672)=2.75, p=0.008, \eta_{p}^{2}=0.028$; not significant were the main effect of the sex, $F(1,96)=0.32, p=0.571, \eta^{2} p=0.003$, or the other interaction effects. The post hoc tests of the scenario effect (see Table 4) showed that, independently of the sex and population, the scenarios with the highest scope scores were the scenarios WI-2, EWI-1-100 and EWI-2-100, which showed significantly higher values 
than all the other scenarios. The scenarios with the lowest scope scores were EWI-1-30, EWI-1-60, EWI-2-30 and EWI-2-60. The mean comparison computed as a function of the population indicated that, independently of the scenario and the sex, Italian participants $(M=7.5)$, showed higher scores on the scope dimension to all the scenarios than Chinese participants $(M=5.9)$. The post hoc tests of the scenario $\times$ population effect showed that the population effect was stronger for the evocative installations with less than $100 \%$ of the covered surface (EWI-1-30, EWI-1-60, EWI-2-30 and EWI-2-60). Finally, the post hoc tests of the scenario $\times$ sex effect showed that females evaluated the scenario EWI-2-30 as having less scope the males.

\subsection{Discussion}

The second experiment clearly shows how participants' restorativeness increases with the number of tiles that constitute the water installations. However, this effect seems to be not linear with the increase in the amount of material. For instance, for both the EWIs, the improvements are neglectable up to $60 \%$ of the covered area, while at $100 \%$ are comparable with those obtained with real installations. The comparison between the two evocative installations did not show relevant differences. As observed in the first study, the general preference of the Italian group toward these installations emerges in almost all the components of restorativeness. Italians evaluated with more fascination $(+1,1$ points), being-away $(+1,2$ points) and scope $(+1,6$ points) than the scenarios.

\section{Conclusions}

The first study has confirmed, over a large sample of participants in both Italy and China, what emerged from previous studies. The introduction of water installations combining sound and visual elements can contribute significantly to improving the restorativeness of individuals in situations characterised by road traffic background noise. This is due to the combination of a well-known acoustic informational masking effect and the use of elements that visually consist of or mimic water. Considering the realistic installations, such as the WI-1 and the WI-2, which represent, respectively, a sea-shoreline and a river, the results have confirmed that the surrounding shape of the river (besides its fascinating effect) provides a physical and mental separation between the position of the participants and outside traffic noise. A similar effect also emerged if one considers the dimension/size of the area which envelopes the elements of the evocative installations. Audio-visual installations, which create a physical and mental separation from outside trafficked environment, help individuals restore more than localised fountains.

In the second study, the results have shown that (besides auditory channels) vision alone is enough to influence individuals' responses positively. With regards to this, the number of tiles that constitute the evocative water installation must cover more than $60 \%$ of the installation area.

The comparison between the Italian and Chinese groups provides evidence that, despite similar trends, the use of the water installations as they were designed for our experiments were less appreciated by the Chinese group. Further studies should be carried out to systematically investigate the influence of more different shapes, colours, and designs of the installations on these two different cultures.

These experiments suggest that by integrating audio-visual installations inside urban parks, it is possible to mitigate the detrimental effect of traffic noise on people's restoration. The effect of informational masking with water sound on road traffic noise, already known from previous research $[48,60,61]$, can be enhanced by providing a visual separation of the areas of interest (where people are expected to stay relaxed) from the boundary of parks.

Moreover, besides using water elements (e.g., small basins and streams), this separation could also be realized by using tiles and other materials that only evoke the shapes and colours of water elements. Attention must be paid to the amount of material used for the evocative installations. In fact, if it is insufficient, the results of the effects can be negligible. 
The design of the evocative water elements has also shown to be perceived differently by the two different groups, suggesting that the visual representation of the water elements could be not consistent among the cultures. This can be very important in order to understand which can be the design key elements among different cultures.

As this research was limited to laboratory studies, it is expected that similar studies can also be performed through in situ experiments [74-76] by including analyses of the acoustics climate of the parks with measurements and noise maps. This would significantly enrich the research material, allowing for a comparison of existing differences between laboratory outcomes and in situ applications.

Author Contributions: Conceptualization, M.M.; data curation, A.P., V.P.S. and S.D.S.; formal analysis, M.M., A.P., V.P.S. and S.D.S.; investigation, M.M., A.P., V.P.S. and S.D.S.; methodology, M.M. and L.M.; resources, M.M., A.P. and C.K.C.; software, A.P.; supervision, L.M. and C.K.C.; validation, V.P.S.; visualization, A.P.; writing—original draft, M.M., A.P., V.P.S. and S.D.S.; writing-review and editing, M.M., L.M., V.P.S. and C.K.C. All authors have read and agreed to the published version of the manuscript.

Funding: This research received no external funding.

Institutional Review Board Statement: Ethical approval was not provided for this study on human participants because data were collected in conformity with the Declaration of Helsinki and the Local Ethics Committee requirements.

Informed Consent Statement: Informed consent was obtained from all subjects involved in the study.

Data Availability Statement: The raw data supporting the conclusions of this article will be made available by the corresponding author, without undue reservation.

Conflicts of Interest: The authors declare no conflict of interest.

\section{References}

1. World Health Organization Regional Office for Europe. Burden of Disease from Environmental Noise: Quantification of Healthy Life Years Lost in Europe. 2011. Available online: https:/ / apps.who.int/iris/handle/10665/326424 (accessed on 25 July 2021).

2. European Parliament. Directive 2002/49/EC of the European Parliament and of the Council of 25 June 2002 relating to the assessment and management of environmental noise. Off. J. Eur. Communities 2002, 189, 12-25.

3. Brown, L. Rethinking "Quiet Areas" as "Areas of High Acoustic Quality". Presented at the 35th International Congress and Exposition on Noise Control Engineering InterNoise, Honolulu, HI, USA, 3-6 December 2006.

4. Pheasant, R.J.; Horoshenkov, K.V.; Watts, G.R.; Barrett, B. The acoustic and visual factors affecting the construction of tranquil spaces in urban and rural environments. J. Acoust. Soc. Am. 2008, 123, 1446-1457. [CrossRef] [PubMed]

5. Cordeau, E.; Gourlot, N. Zones de Calme et Aménagement, Etude Exploratoire sur la Notion de «Zone de Calme», Les Enseignements Pour l'Ile-de-France; Institut d'Aménagement et d'Urbanisme de la Région Ile-de-France (IAURIF): Paris, France, 2006.

6. European Environment Agency. Good Practice Guide on Quiet Areas; Technical Report n. 4/2014; European Environment Agency: Copenhagen, Denmark, 2014.

7. Expert Panel on Noise. Good Practice Guide on Quiet Areas; EEA Report n. 14/2016; European Environment Agency: Copenhagen, Denmark, 2016.

8. Status of Quiet Areas in European Urban Agglomerations; ETC/ATNI 2019/10; European Environment Agency: Copenhagen, Denmark, 2019.

9. Han, B.; Cohen, D.; McKenzie, T.L. Quantifying the contribution of neighborhood parks to physical activity. Prev. Med. 2013, 57, 483-487. [CrossRef]

10. Bancroft, C.; Joshi, S.; Rundle, A.; Hutson, M.; Chong, C.; Weiss, C.C.; Genkinger, J.; Neckerman, K.; Lovasi, G. Association of proximity and density of parks and objectively measured physical activity in the United States: A systematic review. Soc. Sci. Med. 2015, 138, 22-30. [CrossRef] [PubMed]

11. McCormack, G.R.; Rock, M.; Toohey, A.M.; Hignell, D. Characteristics of urban parks associated with park use and physicala ctivity: A review of qualitative research. Health Place 2010, 16, 712-726. [CrossRef] [PubMed]

12. Duan, Y.; Wagner, P.; Zhang, R.; Wulff, H.; Brehm, W. Physical activity areas in urban parks and their use by the elderly from two cities in China and Germany. Lands. Urban Plan. 2018, 178, 261-269. [CrossRef]

13. Liu, H.; Li, F.; Li, J.; Zhang, Y. The relationships between urban parks, residents' physical activity, and mental health benefits: A case study from Beijing, China. J. Environ. Manag. 2017, 190, 223-230. [CrossRef]

14. Kaplan, S. The restorative benefits of nature: Toward an integrative framework. J. Environ. Psychol. 1995, 15, 169-182. [CrossRef]

15. Kaplan, R.; Kaplan, S.; Ryan, R.L. With People in Mind: Design and Management of Everyday Nature; Island Press: Washington, DC, USA, 1998. 
16. Nordh, H.; Hartig, T.; Hagerhall, C.M.; Frya, G. Components of small urban parks that predict the possibility for restoration. Urban For. Urban Green. 2009, 8, 225-235. [CrossRef]

17. Song, C.; Ikei, H.; Igarashi, M.; Miwa, M.; Takagaki, M.; Miyazaki, Y. Physiological and psychological responses of young males during spring-time walks in urban parks. J. Physiol. Anthropol. 2014, 33, 8. [CrossRef]

18. Wang, X.; Rodiek, S.; Wu, C.; Chen, Y.; Li, Y. Stress recovery and restorative effects of viewing different urban park scenes in Shanghai, China. Urban For. Urban Green. 2016, 15, 112-122. [CrossRef]

19. Peters, K.; Elands, B.; Buijs, A. Social interactions in urban parks: Stimulating social cohesion? Urban For. Urban Green. 2010, 9 , 93-100. [CrossRef]

20. Kazmierczak, A.E.; James, P. The role of urban green spaces in improving social inclusion. In Proceedings of the 7th International Postgraduate Research Conference in the Built and Human Environment, University of Salford, Manchester, UK, 28-29 March 2007; Available online: http:/ / usir, salford, ac, uk/11339 (accessed on 25 July 2021).

21. Ayala-Azcárraga, C.; Diaz, D.; Zambrano, L. Characteristics of urban parks and their relation to user well-being. Lands. Urban Plan. 2019, 189, 27-35. [CrossRef]

22. Nilsson, M.E.; Berglund, B. Soundscape quality in suburban green areas and city parks. Acta Acust. United Acust. 2006, 92, 903-911.

23. Brambilla, G.; Gallo, V.; Zambon, G. The Soundscape Quality in Some Urban Parks in Milan, Italy. Int. J. Environ. Res. Public Health 2013, 10, 2348-2369. [CrossRef] [PubMed]

24. Brambilla, G.; Maffei, L. Responses to noise in urban parks and in rural quiet areas. Acta Acustica United Acust. 2006, 92, 881-886.

25. Nouri, A.; Shahmoradi, B.; Darvishi, E.; Gholami, M.; Hajimirzaie, S.; Nasri, O.; Khoshsoorat, O.; Ghaderi, R. Evaluation of noise pollution in Parks of Sanandaj City and zoning with Geographic Information System. J. Adv. Environ. Health Res. 2016, 4, $206-212$.

26. Szeremeta, B.; Trombetta Zannin, P.H. Analysis and evaluation of soundscapes in public parks through interviews and measurement of noise. Sci. Total Environ. 2009, 407, 6143-6149. [CrossRef]

27. Brambilla, G.; De Gregorio, L.; Maffei, L. Soundscape perception of an urban park under flight paths of Naples airport. J. Acoust. Soc. Am. 2005, 117, 2550-2551. [CrossRef]

28. Brambilla, G.; Gallo, V. QUIETE: A scheme for a new index of the environmental quality of green areas. Noise Mapp. 2016, 3, 49-58. [CrossRef]

29. Watts, G.R.; Miah, A.; Pheasant, R.J. Tranquillity and soundscapes in urban green spaces-predicted and actual assessments from a questionnaire survey. Environ. Plan. B 2013, 40, 170-181. [CrossRef]

30. Jabben, J.; Weber, M.; Verheijen, E. A framework for rating environmental value of urban parks. Sci. Total Environ. 2015, 508, 395-401. [CrossRef]

31. Puyana Romero, V.; Maffei, L.; Brambilla, G.; Ciaburro, G. Acoustic, Visual and Spatial Indicators for the Description of the Soundscape of Waterfront Areas with and without Road Traffic Flow. Int. J. Environ. Res. Public Health 2016, 13, 934. [CrossRef]

32. Lavandier, C.; Aumond, P.; Gomez, S.; Dominguès, C. Urban soundscape maps modelled with geo-referenced data. Noise Mapp. 2016, 3, 140-156. [CrossRef]

33. Sztubecka, M.; Skiba, M.; Mrówczyńska, M.; Mathias, M. Noise as a Factor of Green Areas Soundscape Creation. Sustainability 2020, 12, 999. [CrossRef]

34. Szopińska, K. Sustainable Urban Transport and the Level of Road Noise-A Case Study of the City of Bydgoszcz. Geomat. Environ. Eng. 2019, 13, 93-107. [CrossRef]

35. ISIS; PWC. Study on Urban Access Restrictions, Final Report (No. TREN/A4/103-2/2009). European Commission, DG MOVE. 2010. Available online: http:/ / ec.europa.eu/transport/themes/urban/studies/doc/2010_12_ars_final_report.pdf (accessed on 25 July 2021).

36. Maffei, L.; Masullo, M. Electric vehicles and urban noise control policies. Arch. Acoust. 2014, 39, 333-341. [CrossRef]

37. Van Renterghem, T.; Vanhecke, K.; Filipan, K.; Sun, K.; De Pessemier, T.; De Coensel, B.; Joseph, W.; Botteldooren, D. Interactive soundscape augmentation by natural sounds in a noise polluted urban park. Landsc. Urban Plan. 2020, 194, 103705. [CrossRef]

38. Tse, M.S.; Chau, C.K.; Choy, Y.S.; Tsui, W.K.; Chan, C.N.; Tang, S.K. Perception of urban park soundscape. J. Acoust. Soc. Am. 2012, 131, 2762-2771. [CrossRef] [PubMed]

39. Liu, J.; Kang, J.; Luo, T.; Behm, H. Landscape effects on soundscape experience in city parks. Sci. Total Environ. 2013, 454-455, 474-481. [CrossRef]

40. Durlach, N.I.; Mason, C.R.; Kidd, G., Jr.; Arbogast, T.L.; Colburn, H.S.; Shinn-Cunningham, B.G. Note on informational masking. J. Acoust. Soc. Am. 2013, 113, 2984-2987. [CrossRef] [PubMed]

41. De Coensel, B.; Vanwetswinkel, S.; Botteldooren, D. Effects of natural sounds on the perception of road traffic noise. J. Acoust. Soc. Am. 2011, 129, 148-153. [CrossRef]

42. Watts, G.; Pheasant, R.; Horoshenkov, K.; Ragonesi, L. Measurement and subjective assessment of water generated sounds. Acta Acust United Acust. 2009, 95, 1032-1039. [CrossRef]

43. Galbrun, L.; Ali, T.T. Acoustical and perceptual assessment of water sounds and their use over road traffic noise. J. Acoust. Soc. Am. 2013, 133, 227-237. [CrossRef]

44. Rådsten-Ekman, M.; Lundén, P.; Nilsson, M.E. Similarity and pleasantness assessments of water-fountain sounds recorded in urban public spaces. J. Acoust. Soc. Am. 2015, 138, 3043-3052. [CrossRef] 
45. Jeon, J.Y.; Lee, P.J.; Kang, J. Perceptual assessment of quality of urban soundscapes with combined noise sources and water sounds. J. Acoust. Soc. Am. 2010, 127, 1357-1366. [CrossRef] [PubMed]

46. Galbrun, L.; Calarco, F.M.A. Audio-visual interaction and perceptual assessment of water features used over road traffic noise. J. Acoust. Soc. Am. 2014, 136, 2609-2620. [CrossRef]

47. Rådsten-Ekman, M.; Axelsson, Ö.; Nilsson, M.E. Effects of sounds from water on perception of acoustic environments dominated by road-traffic noise. Acta Acust. United Acust. 2013, 99, 218-225. [CrossRef]

48. Jeon, J.Y.; Lee, P.J.; You, J.; Kang, J. Acoustical characteristics of water sounds for soundscape enhancement in urban open spaces. J. Acoust. Soc. Am. 2012, 131, 2101-2109. [CrossRef]

49. Kaplan, R.; Kaplan, S. The Experience of Nature: A Psychological Perspective; Cambridge University Press: Cambridge, NY, USA, 1989.

50. Ulrich, R.S.; Simons, R.F.; Losito, B.D.; Fiorito, E.; Miles, M.A.; Zelson, M. Stress Recovery during Exposure to Natural and Urban Environments. J. Environ. Psychol. 1991, 11, 201-230. [CrossRef]

51. Hartig, T.; Evans, G.W.; Jamner, L.D.; Davis, D.S.; Garling, T. Tracking restoration in natural and urban field settings. J. Environ. Psychol. 2003, 23, 109-123. [CrossRef]

52. Scopelliti, M.; Carrus, G.; Bonaiuto, M. Is it Really Nature That Restores People? A Comparison with Historical Sites with High Restorative Potential. Front. Psychol. 2019, 28, 2742. [CrossRef]

53. Dzhambov, A.; Dimitrova, D. Urban green spaces' effectiveness as a psychological buffer for the negative health impact of noise pollution: A systematic review. Noise Health 2014, 16, 157-165. [CrossRef] [PubMed]

54. Knez, I.; Ode Sang, Å.; Gunnarsson, B.; Hedblom, M. Wellbeing in Urban Greenery: The Role of Naturalness and Place Identity. Front. Psychol. 2018, 9, 491. [CrossRef] [PubMed]

55. White, M.; Smith, A.; Humphryes, K.; Pahl, S.; Snelling, D.; Depledge, M. Blue space: The importance of water for preference, affect, and restorativeness ratings of natural and built scenes. J. Environ. Psychol. 2010, 30, 482-493. [CrossRef]

56. Garrett, J.K.; White, M.P.; Huang, J.; Ng, S.; Hui, Z.; Leung, C.; Tse, L.A.; Fung, F.; Elliott, L.R.; Depledge, M.H.; et al. Urban blue space and health and wellbeing in Hong Kong: Results from a survey of older adults. Health Place 2019, 55, 100-110. [CrossRef]

57. Gascon, M.; Zijlema, W.; Vert, C.; White, M.P.; Nieuwenhuijsen, M.J. Outdoor blue spaces, human health, and well-being: A systematic review of quantitative studies. Int. J. Hyg. Environ. Health 2017, 220, 1207-1221. [CrossRef] [PubMed]

58. Zhang, T.; Liu, J.; Li, H. Restorative Effects of Multi-Sensory Perception in Urban Green Space: A Case Study of Urban Park in Guangzhou, China. IJERPH 2019, 16, 4943. [CrossRef]

59. Lugten, M.; Karacaoglu, M.; White, K.; Kang, J.; Steemers, K. Improving the soundscape quality of urban areas exposed to aircraft noise by adding moving water and vegetation. J. Acoust. Soc. Am. 2018, 144, 2906-2917. [CrossRef] [PubMed]

60. Masullo, M.; Maffei, L.; Pascale, A.; Senese, V.P. An alternative noise mitigation strategy in urban green park: A laboratory experiment. In Proceedings of the Internoise, Hong Kong, China, 27-30 August 2017.

61. Masullo, M.; Pascale, A.; Maffei, L. Effects of combinations of water sounds and visual elements on the road traffic noise mitigation in urban green parks. In Proceedings of the Internoise, Hamburg, Germany, 21-24 August 2016.

62. Senese, V.P.; Pascale, A.; Maffei, L.; Cioffi, F.; Sergi, I.; Gnisci, A.; Masullo, M. Neural Approaches to Dynamics of Signal Exchanges, Smart Innovation, Systems and Technologies; Springer: Singapore, 2020; Volume 151, pp. 347-357.

63. Jiang, L.; Masullo, M.; Maffei, L.; Meng, F.; Vorländer, M. How do shared-street design and traffic restriction improve urban soundscape and human experience?-An online survey with virtual reality. Build. Environ. 2018, 143, 318-328. [CrossRef]

64. Chung, W.K.; Chau, C.K.; Masullo, M.; Pascale, A. Modelling perceived oppressiveness and noise annoyance responses to window views of densely packed residential high-rise environments. Build. Environ. 2019, 157, 124-138. [CrossRef]

65. Schäffer, B.; Pieren, R.; Wissen Hayek, U.; Biver, N.; Grêt-Regamey, A. Influence of visibility of wind farms on noise annoyance-A laboratory experiment with audio-visual simulations. Landsc. Urban Plan. 2018, 186, 67-78. [CrossRef]

66. Echevarria Sanchez, G.M.; Van Renterghem, T.; Sun, K.; De Coensel, B.; Botteldooren, D. Using Virtual Reality for assessing the role of noise in the audio-visual design of an urban public space. Landsc. Urban Plan. 2017, 167, 98-107. [CrossRef]

67. Jeon, J.Y.; In, H. Three-dimensional virtual reality-based subjective evaluation of road traffic noise heard in urban high-rise residential buildings. Build. Environ. 2019, 148, 468-477. [CrossRef]

68. Maffei, L.; Masullo, M.; Pascale, A.; Ruggiero, G.; Puyana Romero, V. On the Validity of Immersive Virtual Reality as tool for multisensory evaluation of urban spaces. Energy Procedia 2015, 78, 471-476.

69. Maffei, L.; Masullo, M.; Pascale, A.; Ruggiero, G.; Puyana Romero, V. Immersive Virtual Reality in community planning: Acoustic and visual congruence of simulated vs real world. Sustain. Cities Soc. 2016, 27, 338-345. [CrossRef]

70. Pasini, M.; Berto, R.; Brondino, M.; Hall, R.; Ortner, C. How to measure the restorative quality of environments: The PRS-11. Procedia Soc. Behav. Sci. 2014, 159, 293-297. [CrossRef]

71. Pascale, A.; Masullo, M.; Maffei, L. Mitigazione del rumore da traffico veicolare mediante suoni naturali. In Proceedings of the $43^{\circ}$ Convegno Nazionale dell'Associazione Italiana di Acustica (AIA), Alghero, Italy, 25-27 May 2016.

72. Hartig, T.; Korpela, K.; Evans, G.W.; Garling, T. A measure of restorative quality of environments. Scand. Hous. Plan. Res. 1997, 14, 175-194. [CrossRef]

73. Tabachnick, B.G.; Fidell, L.S. Using Multivariate Statistics, 3rd ed.; Harper Collins College Publisher: New York, NY, USA, 1996.

74. Steele, D.; Bild, E.; Tarlao, C.; Guastavino, C. Soundtracking the public space: Outcomes of the musikiosk soundscape intervention. Int. J. Environ. Res. Public Health 2019, 16, 1865. [CrossRef] 
75. Cerwén, G. Urban soundscapes: A quasi-experiment in landscape architecture. Landsc. Res. 2016, 41, 481-494. [CrossRef]

76. Steele, D.; Fraisse, V.; Bild, E.; Guastavino, C. Bringing music to the park: The effect of Musikiosk on the quality of public experience. Appl. Acoust. 2021, 177, 107910. [CrossRef] 